OPEN ACCESS

Edited by:

Philip S. Clifford,

University of Illinois at Chicago,

United States

Reviewed by:

Scott Dankel,

Rowan University, United States

Steve Segal,

University of Missouri, United States

*Correspondence:

Alexander Franz

alexander.franz@hhu.de

Michael Behringer

behringer@sport.uni-frankfurt.de

Specialty section:

This article was submitted to

Exercise Physiology,

a section of the journal

Frontiers in Physiology

Received: 15 October 2020 Accepted: 27 November 2020 Published: 16 December 2020

Citation:

Franz A, Berndt F, Raabe J, Harmsen J-F, Zilkens $C$ and

Behringer M (2020) Invasive

Assessment of Hemodynamic, Metabolic and lonic Consequences

During Blood Flow Restriction

Training. Front. Physiol. 11:617668. doi: 10.3389/fphys.2020.617668

\section{Invasive Assessment of Hemodynamic, Metabolic and Ionic Consequences During Blood Flow Restriction Training}

\author{
Alexander Franz ${ }^{1,2 *}$, Felix Berndt ${ }^{1}$, Joachim Raabe ${ }^{3}$, Jan-Frieder Harmsen ${ }^{4}$, \\ Christoph Zilkens ${ }^{1,2}$ and Michael Behringer ${ }^{5 *}$
}

${ }^{1}$ Department of Orthopedics, University Hospital Duesseldorf, Düsseldorf, Germany, ${ }^{2}$ Department of Adult Reconstruction, ATOS Orthoparc Clinic Cologne, Cologne, Germany, ${ }^{3}$ Department of Anesthesiology, University Hospital Duesseldorf, Düsseldorf, Germany, ${ }^{4}$ Department of Nutrition and Movement Sciences, School for Nutrition and Translational Research in Metabolism, Maastricht University Medical Center, Maastricht, Netherlands, ${ }^{5}$ Department of Sports Medicine and Exercise Physiology, Goethe University Frankfurt, Frankfurt, Germany

Purpose: Medically recommended training often faces the dilemma that necessary mechanical intensities for muscle adaptations exceed patients' physical capacity. In this regard, blood flow restriction (BFR) training is becoming increasingly popular because it enables gains in muscle mass and strength despite using low-mechanical loads combined with external venous occlusion. Since the underlying mechanisms are still unknown, we applied invasive measurements during exercise with and without BFR to promote physiological understanding and safety of this popular training technique.

Methods: In a randomized cross-over design, ten healthy men (28.1 \pm 6.5 years) underwent two trials of unilateral biceps curls either with (BFR) and without BFR (CON). For analysis of changes in intravascular pressures, blood gases, oximetry and electrolytes, an arterial and a venous catheter were placed at the exercising arm before exercise. Arterial and venous blood gases and intravascular pressures were analyzed before, during and 5 min after exercise.

Results: Intravascular pressures in the arterial and venous system were more increased during exercise with BFR compared to CON ( $p<0.001)$. Furthermore, arterial and venous blood gas analyses revealed a BFR-induced metabolic acidosis $(p<0.05)$ with increased lactate production $(\rho<0.05)$ and associated elevations in $\left[\mathrm{K}^{+}\right]$, $\left[\mathrm{Ca}^{2+}\right]$ and $\left[\mathrm{Na}^{+}\right](p<0.001)$.

Conclusion: The present study describes for the first time the local physiological changes during BFR training. While BFR causes greater hypertension in the arterial and venous system of the exercising extremity, observed electrolyte shifts corroborate a local metabolic acidosis with concurrent rises in $\left[\mathrm{K}^{+}\right]$and $\left[\mathrm{Na}^{+}\right]$. Although BFR could be a promising new training concept for medical application, its execution is associated with comprehensive physiological challenges.

Keywords: venous occlusion, kaatsu training, rehabilitation, hyperkalemia, acidosis, resistance training, physical training 


\section{INTRODUCTION}

Training patients to maintain or improve muscle mass often faces a dilemma as the lower limit of recommended loads for resistance training ( $>50 \%$ one repetition maximum, 1RM) often exceeds the patients' physical capacity. Over the last two decades, however, there has been growing evidence that the original recommendations for exercise intensity are no longer tenable. According to these data, $20-30 \%$ of the individual 1RM is sufficient to achieve muscle mass and strength gains when the blood supply to the working muscles is restricted and venous return is blocked (Patterson et al., 2019). This type of training is known as blood flow restriction training (BFR-training) and is becoming increasingly popular in recreational and competitive sports. However, due to the low mechanical load required, this training method has recently moved into the clinical focus (Cristina-Oliveira et al., 2020).

Numerous studies are already available that have examined BFR-training in the context of rehabilitation and prehabilitation of different entities (Hughes et al., 2019; Lu et al., 2020). Especially in orthopedic rehabilitation, BFR-training is expected to play a major role in the future since its application can reduce postoperative muscle loss and arthrogenic muscle inhibition (Hughes et al., 2017; Conceição and Ugrinowitsch, 2019). However, most available studies focus on improving physical fitness, leaving a lack of knowledge about the trainingrelated changes in the occluded extremity. Venous pooling raises questions like what pressures the venous vascular system is exposed to and what electrolyte changes occur in the unilaterally closed compartment. Therefore, it can currently only be speculated to which physiological stress the body is exposed during BFR-training (Minniti et al., 2020). To assess the physiological consequences of BFR-training on a local and systemic level, we performed an invasive catheter approach to measure changes in hemodynamic, metabolic and ionic balance during low-load BFR-training in both the arterial and venous system.

\section{MATERIALS AND METHODS}

\section{Subjects}

Ten healthy male subjects (age: $28.1 \pm 6.5$ years) volunteered for this study (Table 1). All subjects were experienced in resistance training, had no prior experiences with BFR-Training and reported not having performed regular strength training 1 week before the start of the study. Subjects were informed about the experimental procedures and possible risks and signed an informed consent document before the investigation. The study was approved by the local Ethics Committee of the University Hospital Duesseldorf (Trial-ID: 2015104498) and was performed according to the Declaration of Helsinki.

\section{Study Design}

To investigate the effects of BFR on local and systemic physiological adaptations in comparison to a training without $\mathrm{BFR}$, a randomized cross-over design was applied. The ten included subjects performed an exercise protocol for the elbow
TABLE 1 | Basic characteristics of subjects.

\begin{tabular}{lc}
\hline Subjects $(\boldsymbol{n}=\mathbf{1 0})$ & \\
Height $(\mathrm{cm})$ & $185.6 \pm 8.9 \mathrm{~cm}$ \\
Weigth $(\mathrm{kg})$ & $86.7 \pm 8.0 \mathrm{~kg}$ \\
$1 \mathrm{RM} / 30 \%$ of $1 \mathrm{RM}$ & $23.4 \pm 3.4 \mathrm{~kg} / 7.0 \pm 1.0 \mathrm{~kg}$ \\
$\mathrm{LOP} / 50 \%$ of LOP & $156 \pm 13 \mathrm{mmHg} / 77.9 \pm 6.5 \mathrm{mmHg}$ \\
\end{tabular}

flexors for two times, once with and once without BFR, separated by 4 weeks of rest. To control the impact of the repeated-bouteffect (Hyldahl et al., 2017), participants were randomized via a random-number table to start with either the control training trial (CON) $(n=5)$ or the BFR training session (BFR) $(n=5)$. Therefore, all subjects reported to the laboratory for three testing sessions and follow-up measurements.

During the first visit, subjects' individual concentric 1RM of the elbow flexor of the dominant arm was determined in accordance to Jessee et al. (2017). After 2 weeks of rest, the second visit was performed by carrying out the experimental loading for the first time. After 4 weeks, the third laboratory visit was performed to repeat the experimental loading as cross-over (Figure 1).

\section{Sample Size Calculation}

Although to the best of our knowledge no data are available on the change in intravenous pressure during BFR training, we assumed that venous pooling leads to a moderate to high effect $(f=0.3)$ with respect to this main outcome. Based on this assumption, we calculated for a repeated measures design (within-between interaction) a required sample size of 10 subjects using the $\mathrm{G}^{*}$ Power software version 3.1.9.4. The minimal significance $(\alpha)$ and statistical power $(1-\beta)$ were set at 0.05 and 0.80 , respectively.

\section{Interventions}

The exercise protocol consisted of unilateral biceps curls with the dominant arm by using a dumbbell (ScSports, Emmerich, Germany) that were performed for four sets, containing 75 repetitions (reps) (1. Set: 30 reps, 2.-4. Set: 15 reps), at 30\% of subjects individual concentric 1RM. The rest between sets was $30 \mathrm{~s}$. Subjects were standing in an upright position, with the back leaning against a wall. Throughout the execution of the exercise, the elbow continuously held contact with the wall. For each repetition, the dumbbell was lifted to a full elbow flexion ( $\sim 50$ degrees). The duration of each repetition was set to $4 \mathrm{~s}, 2 \mathrm{~s}$ for the concentric as well as for the eccentric phase, controlled by a metronome ( 60 beats per min). The set was stopped when volutional failure occured or if the subject was not able to keep the pace.

The BFR-intervention was performed by using 50\% of the individual arterial limb occlusion pressure (LOP). For determination of the LOP, the inflatable tourniquets of $11.5 \mathrm{~cm}$ width were placed proximal at the exercising arm before the training session (PBFR, Delfi medical Inc., Vancouver, Canada). After a 10-min rest period, LOP was determined sonographically in a lying position by displaying the radial artery with an 
ultrasound device and using a Doppler to assess the blood flow within the vessel. Subsequently, the cuff was inflated until no further blood flow was detectable. This pressure was defined as the individual LOP.

\section{Arterial and Venous Blood Sampling and Analysis}

To assess intravascular changes in pressure, blood gases and ionic homeostasis, an arterial as well as a venous catheter were placed into the dominant arm before exercise (Zavorsky et al., 2005). For this purpose, subjects were placed in a lying position on a standard medical examination table. Under local anesthesia with lidocaine hydrochloride, Seldinger's technique was used to puncture the radial artery for the arterial access and a dorsal hand vein (Rete venosum dorsale manus) for the venous access, respectively (Figure 2 ).

For determination of intravascular pressures, sensor needles (20 gauge) linked to a line containing a continuous column of saline connected to a transducer unit were used (LogiCal Pressure Monitoring Kit, Smiths medical int. Ltd., UK). The system was calibrated outside the tissue at the patient's heart level in a standing position. Changes in intravascular pressures, arterial and venous blood gas analyses (BGA) (safePICO sampler, Radiometer $\mathrm{GmbH}$, Krefeld, Germany) were collected before exercise, in between the four exercise sets as well as immediatelyand $5 \mathrm{~min}$ after the exercise protocol (Figure 1). Prior to each collection of samples for BGA, an amount of about $5 \mathrm{ml}$ blood was initially collected from the catheters with a syringe and discarded. Subsequently, a total volume of about $2 \mathrm{ml}$ was taken for each BGA at each time point from the arterial and venous catheter. Since we measured arterial and venous BGA at six time points, a total volume of about $84 \mathrm{ml}$ was taken throughout one test session. The obtained BGA were analyzed directly via the ABL800 FLEX BGA system (Radiometer GmbH, Krefeld, Germany). All examinations, preparations and maintenance associated with the invasive work on the catheters were carried out under sterile conditions.

For monitoring of cardiovascular responses, systolic blood pressure (SBP), diastolic blood pressure (DBP), mean arterial pressure (MAP) and peripheral venous pressure (PVP) were

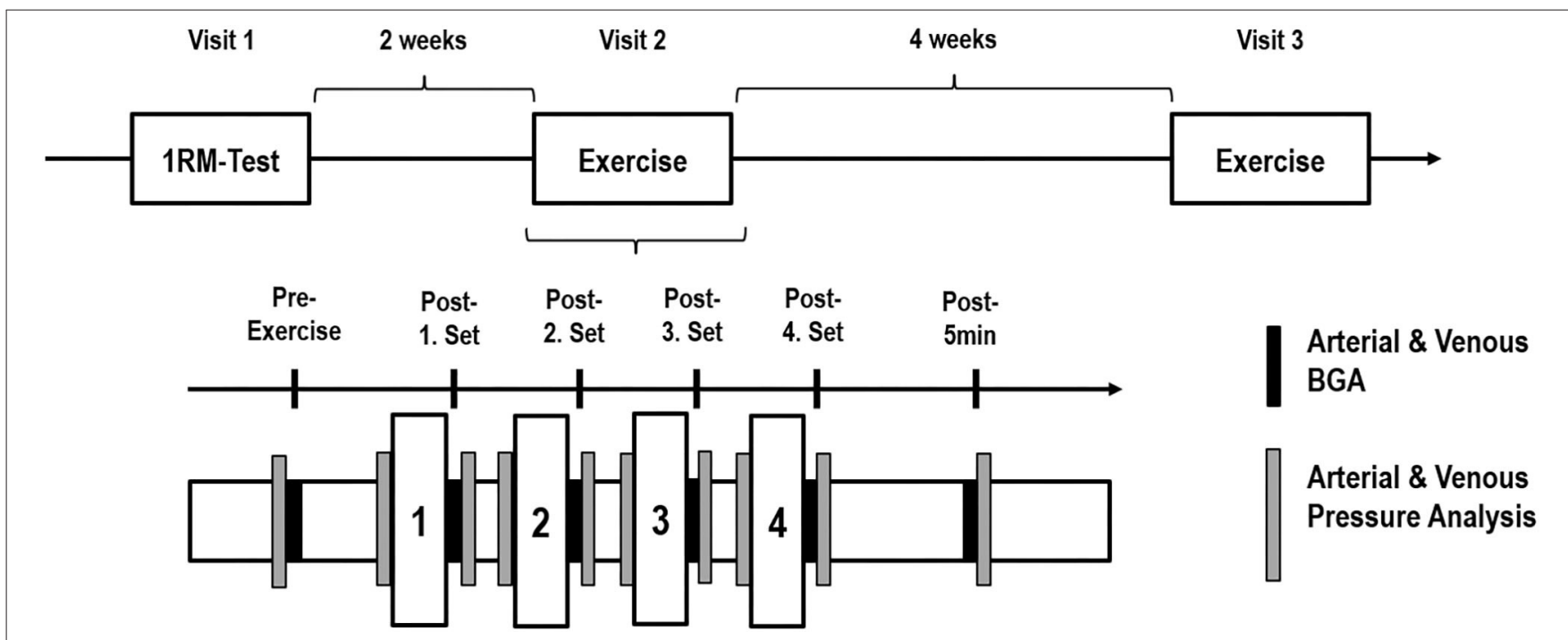

FIGURE 1 | Study design. (Above) Graphical overview of the three appointments on a timeline with the corresponding rest phases. (Below) Illustration of the experimental protocol with four sets and the time-points of sample and data collection. 1RM, one repetition maximum; BGA, blood gas analysis.
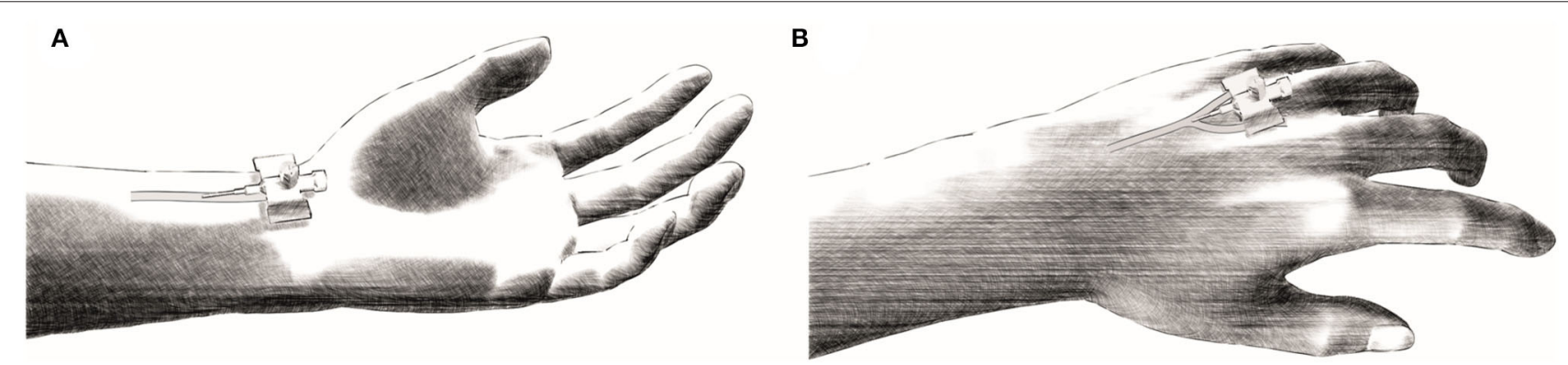

FIGURE 2 | Schematic representation of the puncture locations for the invasive catheters. (A) Under local anesthesia the radial artery was punctured sonographically for the placement of the arterial catheter. (B) The venous catheter was placed in the venous plexus (Rete venosum dorsale manus) of the back of the hand. 
determined. Additionally, the following BGA-parameters were obtained from the arterial (a-) and venous (v-) system: Carbon dioxide partial pressure $\left[\mathrm{p}\left(\mathrm{CO}_{2}\right)\right]$, oxygen partial pressure $\left[\mathrm{p}\left(\mathrm{O}_{2}\right)\right]$, oxygen content $\left(\mathrm{ctO}_{2}\right)$, oxyhemoglobin fraction $\left(\mathrm{FO}_{2} \mathrm{Hb}\right)$, hemoglobin content $(\mathrm{ctHb})$, oxygen half-saturation pressure of hemoglobin ( $\mathrm{p} 50)$ as well as the concentration of lactate $\left[\left(\mathrm{La}^{-}\right)\right]$, potassium $\left[\left(\mathrm{K}^{+}\right)\right]$, sodium $\left[\left(\mathrm{Na}^{+}\right)\right]$, calcium $\left[\left(\mathrm{Ca}^{2+}\right)\right]$, bicarbonate $\left[\left(\mathrm{HCO}_{3}^{-}\right)\right]$, and chloride $\left[\left(\mathrm{Cl}^{-}\right)\right]$.

\section{Statistics}

Two-way repeated measures ANOVAs were used to compare changes in measures over time between BFR and CON. In cases of no condition by time interaction, we interpreted the main effects for condition (BFR vs. CON) and time, and in the case of statistical significance, we followed up the respective main effects with pairwise comparisons using Bonferroni post hoctests. By contrast, in cases of a significant condition by time interaction, we tested for simple main effects. All statistical analyses were performed with the GraphPad Prism 8 software package (GraphPad Software, San Diego, CA, USA). Results are expressed as means \pm standard deviations. Statistical significance was accepted at $p<0.05$.

\section{RESULTS}

In the BFR trial, participants were not able to perform the same amount of repetitions beginning in the second set leading to a shorter time under tension in the last three sets $(p<0.001)$. Table 2 presents outcomes related to exercise performance during the four sets. At Pre, before exercise, no significant differences between conditions were detected in any outcome parameter.

\section{Cardiovascular Outcomes}

Heart rate (HR) and all intravascular pressure parameters increased showing significant time effects $(p<0.001)$ as shown in Figure 3. For HR, DBP (Figure 3A), and MAP (Figure 3B), there were no significant differences between conditions at any time point. SBP and PVP showed additionally a significant condition ( $p=0.002$ and $p<0.001$, respectively) and interaction effect (for both $p<0.001)$. SBP was higher in BFR compared to CON after all four sets and at Pre-Set $4(p<0.05)$ with the greatest difference at Post-Set $2(162 \pm 15 \mathrm{mmHG}$ vs. $141 \pm 12 \mathrm{mmHG}, p<0.001$, Figure 3C). From Post-Set 1 to Post-Set 4, BFR demonstrated higher PVP values compared to CON $(p<0.001)$ with the greatest difference at Post-Set $1(65 \pm 14 \mathrm{mmHG}$ vs. $23 \pm 7$ $\mathrm{mmHG}$, Figure 3D).

\section{Blood Gas Analysis}

Arterial and venous $\mathrm{pH}, \mathrm{p}\left(\mathrm{O}_{2}\right), \mathrm{p}\left(\mathrm{CO}_{2}\right), \mathrm{p} 50, \mathrm{ctO}_{2}, \mathrm{ctHb},\left[\mathrm{K}^{+}\right]$, $\left[\mathrm{Na}^{+}\right],\left[\mathrm{La}^{-}\right],\left[\mathrm{HCO}_{3}^{-}\right]$, and venous $\mathrm{FO}_{2} \mathrm{Hb}$ all showed significant time effects. A significant condition effect was revealed for arterial and venous $\mathrm{p}\left(\mathrm{CO}_{2}\right)$ and $\mathrm{pH}$, and venous $\mathrm{ctHb}, \mathrm{FO}_{2} \mathrm{Hb},\left[\mathrm{Na}^{+}\right]$, and $\left[\mathrm{La}^{-}\right]$. A significant interaction effect was revealed for arterial and venous $\mathrm{pH}, \mathrm{ctO}_{2},\left[\mathrm{La}^{-}\right]$and $\left[\mathrm{HCO}_{3}^{-}\right]$, and venous $\mathrm{p}\left(\mathrm{O}_{2}\right)$, $\mathrm{p}\left(\mathrm{CO}_{2}\right), \mathrm{p} 50, \mathrm{FO}_{2} \mathrm{Hb},\left[\mathrm{K}^{+}\right],\left[\mathrm{Na}^{+}\right]$and a-ctHb (for the main blood gases see Figure 4, for electrolytes see Figure 5). All results of outcomes from blood gas analysis that are not presented in figures are summarized in Table 3.

After each of the four sets, a-pH was higher in BFR compared to $\mathrm{CON}$ ( $p \leq 0.001$, Figure 4A). For v-pH, BFR demonstrated a more pronounced drop with lower values at Post-Set $2(7.23 \pm$ 0.05 vs. $7.30 \pm 0.06, p=0.014)$ and Post-Set 4 (7.24 \pm 0.06 vs. 7.31 $\pm 0.05, p=0.015$ ) compared to CON (Figure 4B). Only in BFR, the $\mathrm{v}-\mathrm{p}\left(\mathrm{O}_{2}\right)$ was decreased after all four sets compared to Pre $(p$ $<0.001$, Figure 4C). BFR demonstrated a greater increase in $\mathrm{v}$ $\mathrm{p}\left(\mathrm{CO}_{2}\right)$ with higher levels at Post-Set 2 compared to CON (67.0 $\pm 8.6 \mathrm{mmHG}$ vs. $54.2 \pm 11.7 \mathrm{mmHG}, p=0.017$, Figure 4D). At Post-Set2, v-p50 was higher in BFR compared to CON ( $p=$ $0.043)$. $\mathrm{V}-\mathrm{FO}_{2} \mathrm{Hb}$ was lower in BFR compared to CON at PostSet $1(46.1 \pm 21.4 \%$ vs. $71.4 \pm 18.6 \%, p=0.009)$ and Post-Set 4 $(48.4 \pm 22.8 \%$ vs. $69.9 \pm 17.8 \%, p=0.040)$.

Only in CON, a-[La $\left.{ }^{-}\right]$were already decreased 5 min PostExercise compared to Post-Set $4(2.7 \pm 0.8 \mathrm{mmol} / \mathrm{L}, p=0.004$, Figure 5A). After the second until the fourth set, $\mathrm{v}-\left[\mathrm{La}^{-}\right]$were significantly higher in BFR compared to CON $(p<0.05)$ with the greatest difference Post-Set $4(7.5 \pm 2.7 \mathrm{mmol} / \mathrm{L}$ vs. $4.3 \pm$ $1.1 \mathrm{mmol} / \mathrm{L}, p<0.001$, Figure 5B). Whereas, in BFR a- $\left[\mathrm{HCO}_{3}^{-}\right]$ were only significantly decreased $5 \mathrm{~min}$ Post-Exercise $(22.0 \pm$ $2.8 \mathrm{mmol} / \mathrm{L}$ vs. $24.2 \pm 0.9 \mathrm{mmol} / \mathrm{L}, p<0.001)$, reductions in CON started at Post-Set 2 and persisted thereafter $(p<0.05$, Figure 5C). In $\mathrm{CON}$, reduced $\mathrm{v}-\left[\mathrm{HCO}_{3}^{-}\right]$were present at all post measurements $(p=0.05)$ except for Post-Set $2(p=0.214)$, and in BFR at Post-Set 2 until Post-Set $4(p<0.001$, Figure 5D).

TABLE 2 | Outcomes related to exercise performance during the four sets with blood flow restriction (BFR) and without (Control).

\begin{tabular}{|c|c|c|c|c|c|c|c|c|}
\hline & \multirow[b]{2}{*}{ Condition } & \multirow[b]{2}{*}{ Set 1} & \multirow[b]{2}{*}{ Set 2} & \multirow[b]{2}{*}{ Set 3} & \multirow[b]{2}{*}{ Set 4} & \multicolumn{3}{|c|}{$p$-values from 2 way ANOVA } \\
\hline & & & & & & Time & Condition & Interaction \\
\hline \multirow[t]{2}{*}{ Repetitions [ $n]$} & Control & $30 \pm 0$ & $15 \pm 0$ & $15 \pm 0$ & $15 \pm 0$ & $<0.001$ & $<0.001$ & $<0.001$ \\
\hline & BFR & $29 \pm 2$ & $11 \pm 3^{\#}$ & $8 \pm 2^{\#}$ & $7 \pm 2^{\#}$ & & & \\
\hline \multirow[t]{2}{*}{ Time under tension [s] } & Control & $113 \pm 6$ & $58 \pm 5$ & $58 \pm 6$ & $57 \pm 6$ & $<0.001$ & $<0.001$ & $<0.001$ \\
\hline & BFR & $114 \pm 7$ & $50 \pm 6^{\#}$ & $40 \pm 8^{\#}$ & $35 \pm 8^{\#}$ & & & \\
\hline \multirow[t]{2}{*}{ Rest period after set [s] } & Control & $37 \pm 6$ & $37 \pm 5$ & $36 \pm 5$ & n.a. & 0.287 & 0.921 & 0.776 \\
\hline & BFR & $38 \pm 7$ & $37 \pm 10$ & $35 \pm 6$ & n.a. & & & \\
\hline
\end{tabular}

\footnotetext{
\#Significantly different between conditions ( $p<0.05)$.
} 

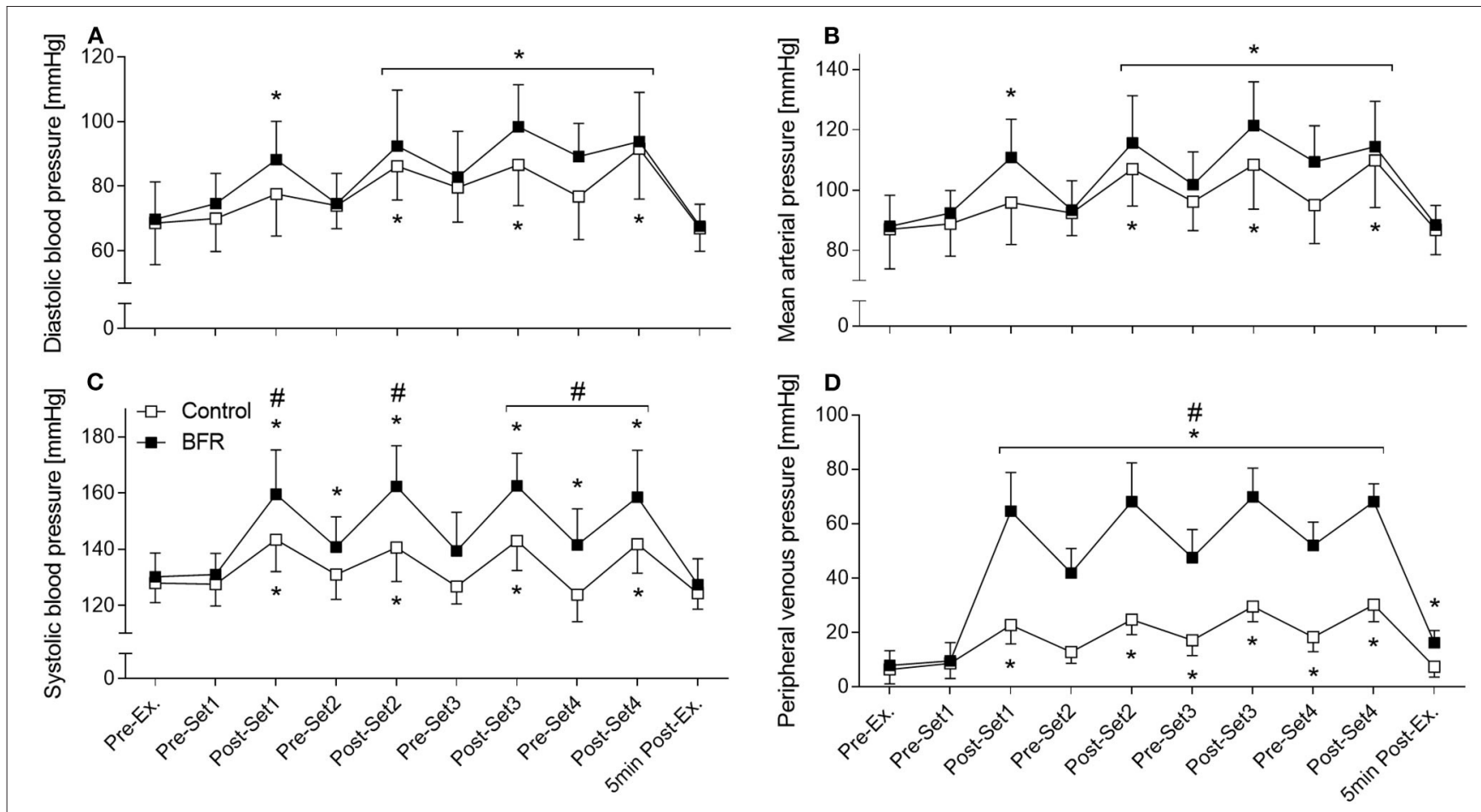

FIGURE 3 | Intravascular pressure parameters. (A) diastolic blood pressure, (B) mean arterial pressure, (C) systolic blood pressure, (D) peripheral venous pressure. *Significantly different from Pre within the respective condition $(p<0.05)$. \# Significantly different between conditions $(p<0.05)$.

After each of the four sets $\mathrm{v}-\left[\mathrm{K}^{+}\right]$were only significantly elevated in BFR $(p<0.001)$, and at Post-Set 1 this was higher than in CON $(5.0 \pm 1.0 \mathrm{mmol} / \mathrm{L}$ vs. $4.1 \pm 0.9 \mathrm{mmol} / \mathrm{L}, p=0.019$, Figure 5E). In $\mathrm{CON}, \mathrm{v}-\left[\mathrm{Na}^{+}\right]$were only significantly elevated at Post-Set $1(142.2 \pm 2.0 \mathrm{mmol} / \mathrm{L}$ vs. $140.1 \pm 1.7 \mathrm{mmol} / \mathrm{L}, p=$ 0.048), whereas in BFR, elevations were significant after each of the four sets $(p<0.05$, Figure 5F). Only in BFR, a-ctHb was elevated at all post-measurements $(p<0.01)$. Figures for all other parameters can be found in the Supplementary Figures 1, 2.

\section{DISCUSSION}

The present study is the first to measure changes in intravascular pressures, blood gases, oximetry, and electrolytes during BFR in the occluded limb.

\section{Intravascular Pressures and Cardiovascular Response}

During exercise, mechanical and/or metabolic stress can induce systemic adjustments within the cardiovascular system, which is called exercise pressor reflex (Spranger et al., 2015; Wan et al., 2020). The present findings support the occurrence of the exercise pressor reflex as unilateral biceps curls with $30 \%$ of the $1 \mathrm{RM}$ resulted in elevations of $\mathrm{HR}, \mathrm{SBP}$ and $\mathrm{DBP}$ compared to baseline even in CON. Furthermore, our data reveal a greater increase in SBP through BFR after all sets in comparison to $\mathrm{CON}$, which is consistent with previous measurements at the contralateral arm (Brandner et al., 2015) or changes induced by BFR of the lower extremity (Poton and Polito, 2015).

While the present findings rely on young and trained subjects, research in older populations indicate that low intensity BFR can cause higher arterial pressures even in comparison to regular high intensity training (Scott et al., 2018). Therefore, it needs to be highlighted that BFR induces a more pronounced cardiovascular response than low intensity training alone, which has to be considered in the practical application of BFR training in different populations.

In line with the obtained findings in the arterial system, the present data also indicate BFR-induced venous hypertension. In relation to previously reported increased membrane permeability (Wernbom et al., 2012) and reductions in plasma volume upon BFR-training (Sato et al., 2005), venous hypertension could explain the muscle swelling often observed after BFR (Freitas et al., 2017). Venous hypertension suggests an increase in the hydrostatic filtration pressure within the capillary bed supporting the frequently discussed contribution of BFR-induced muscle swelling to muscle anabolism (Loenneke et al., 2012).

However, our findings regarding the impact of BFR on the venous system provide important information on the applicability of this training method. Considering that in a standing position at rest gravity causes a hydrostatic venous hypertension of about $35 \mathrm{mmHg}$ at the hand and $90 \mathrm{mmHg}$ above the ankle (Arnoldi, 1965; Tansey et al., 2019), BFR-training can enhance hypertension by $\sim 60 \mathrm{mmHg}$. Whereas this condition 
A

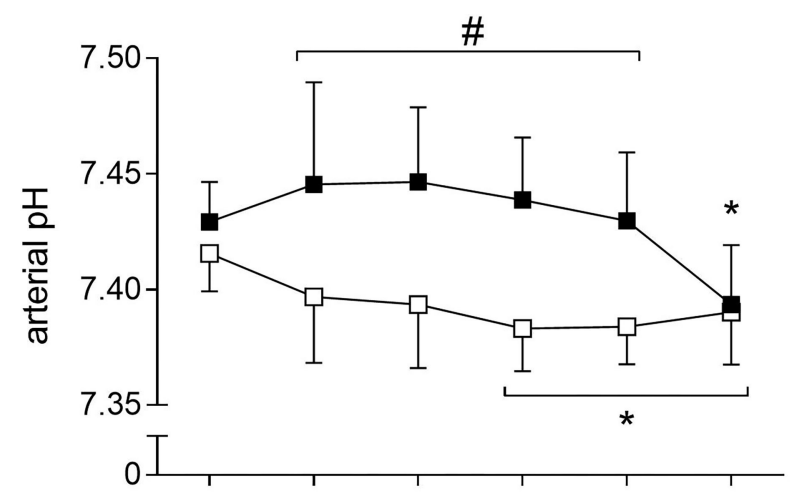

C

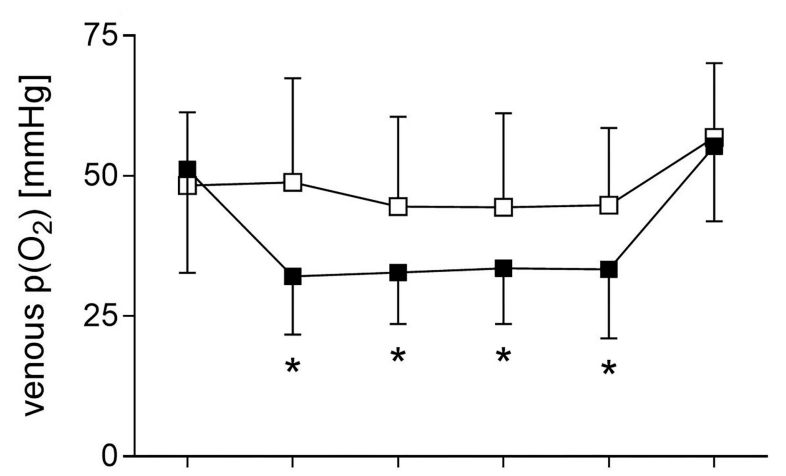

E

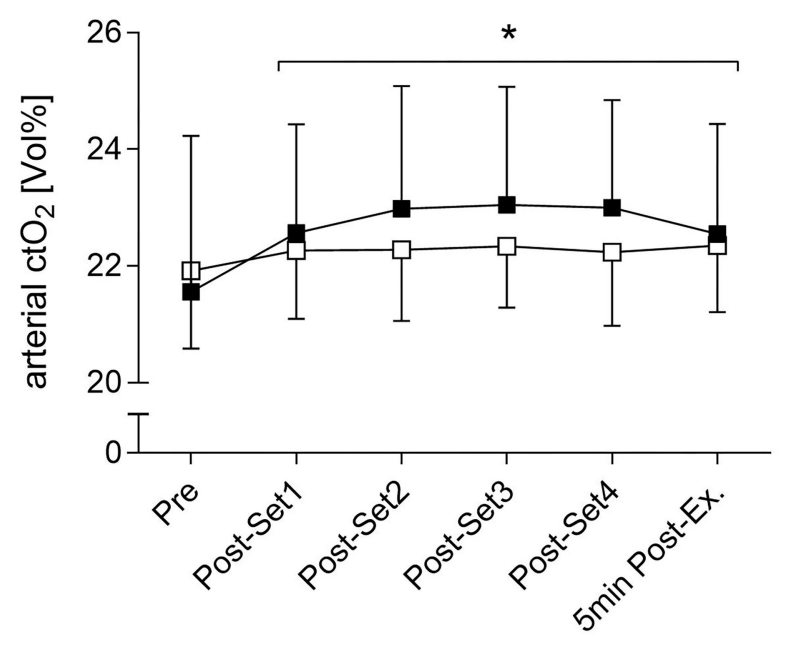

B

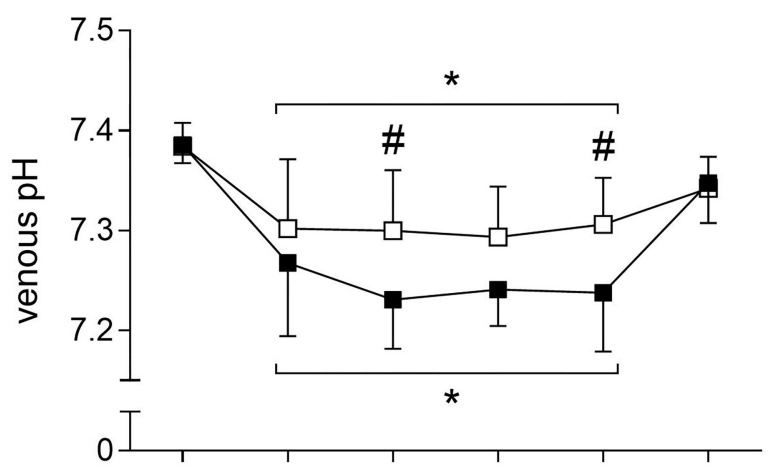

D

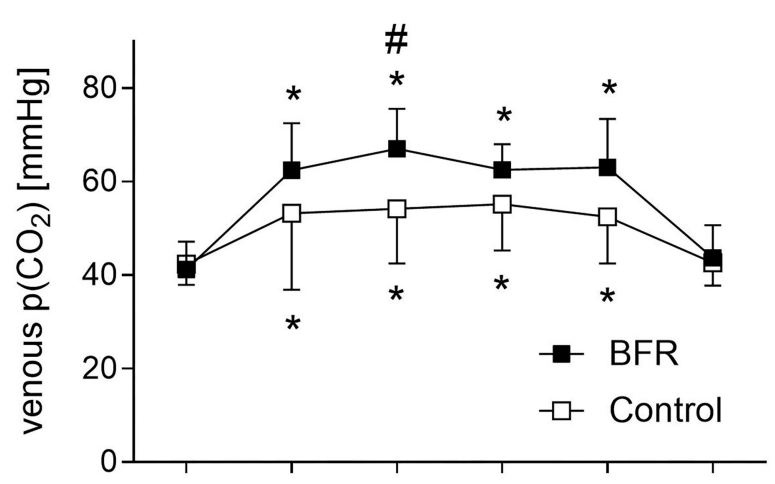

$\mathbf{F}$

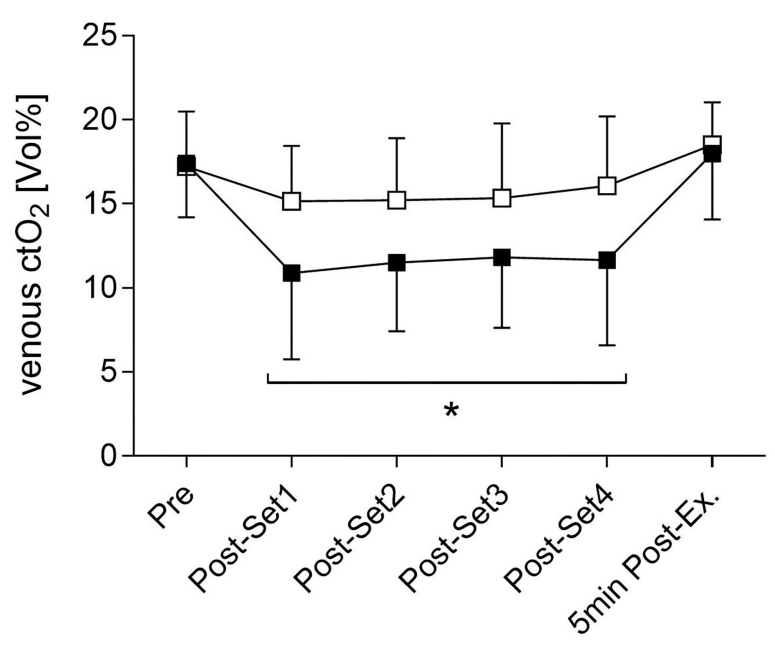

FIGURE 4 | Main blood gas parameters with a significant interaction effect. (A) arterial pH, (B) venous pH, (C) venous $p\left(\mathrm{O}_{2}\right),(\mathbf{D})$ venous $\mathrm{p}\left(\mathrm{CO}_{2}\right),(\mathbf{E})$ arterial ctO 2 , (F) venous $\mathrm{ctO}_{2}$. ${ }^{*}$ Significantly different from Pre within the respective condition $(p<0.05)$. \# Significantly different between conditions $(p<0.05)$.

can be tolerated by a healthy venous system with functioning venous valves which prevent a pathological venous reflux (Sarin et al., 1992), patients with venous insufficiency or postoperative lymphedema could experience worsening of their cardiovascular health status through BFR-training.

\section{Blood Gases and Oximetry}

To quantify changes in oxygen supply during exercise, BGA and oximetry data from arterial and venous blood samples were analyzed. Based on previously reported reductions in arterial blood flow (Kilgas et al., 2019) and tissue oxygenation during 
A

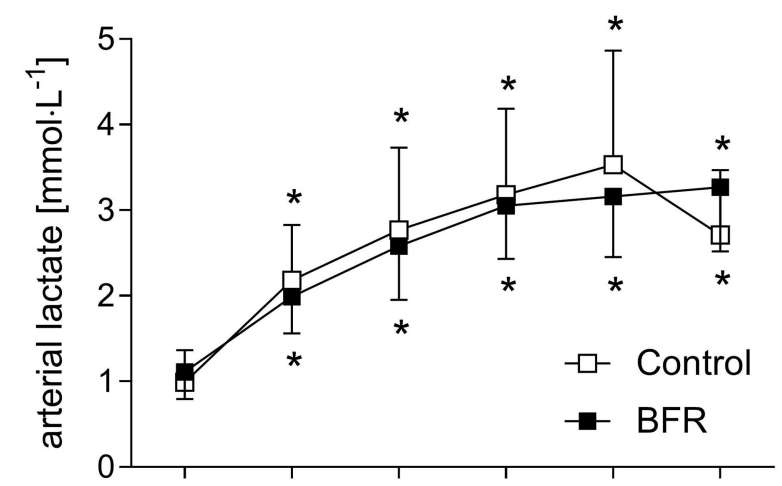

C

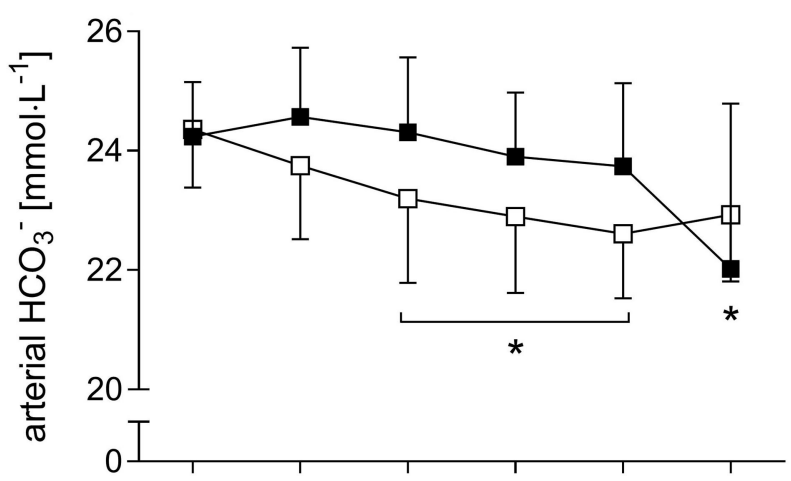

E

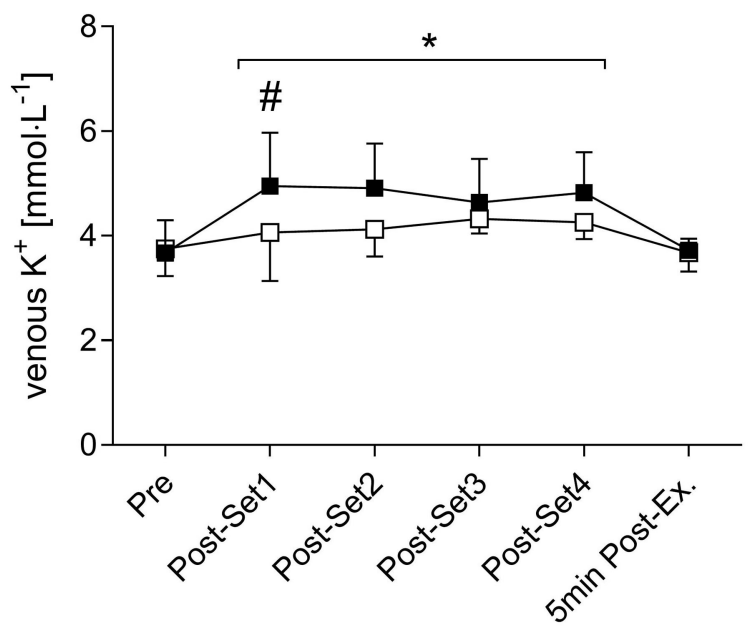

B

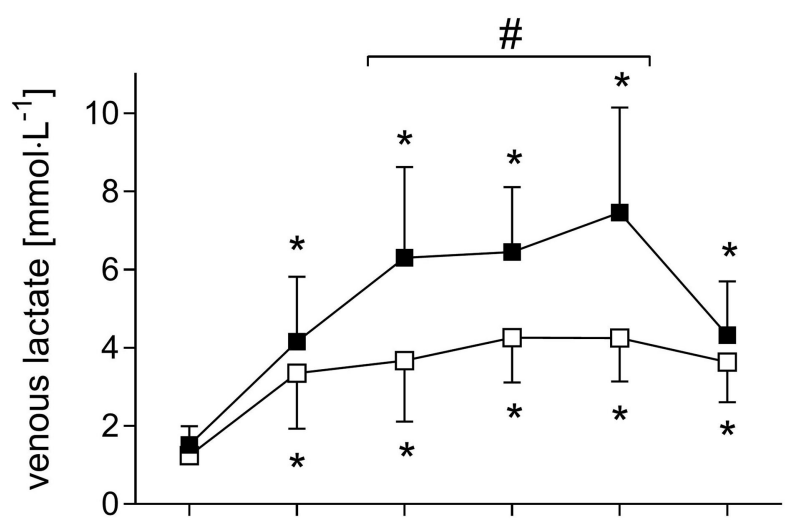

D

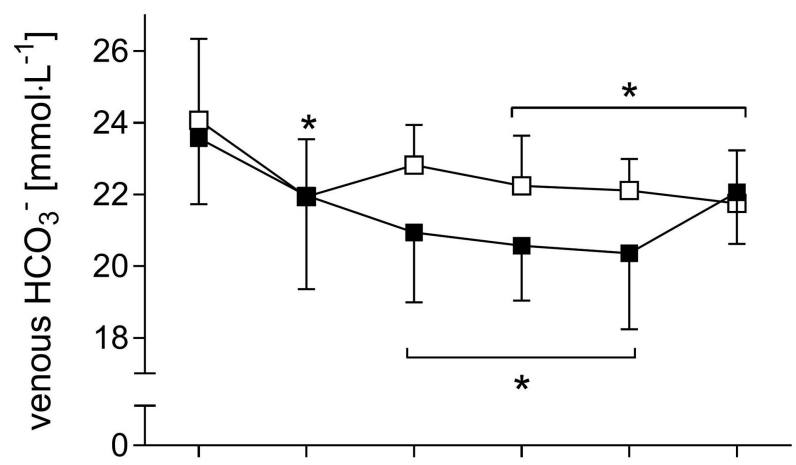

$\mathbf{F}$

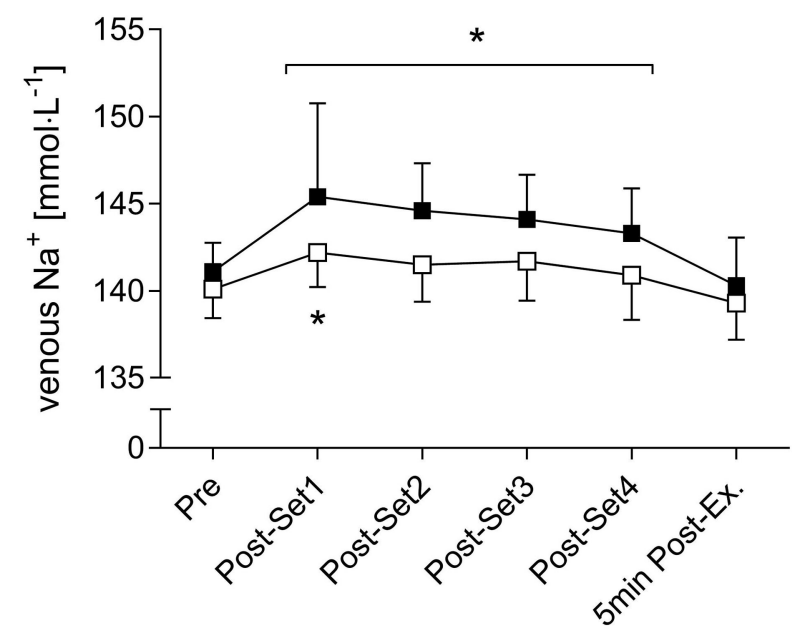

FIGURE 5 | Electrolytes with a significant interaction effect. (A) arterial lactate, (B) venous lactate, (C) arterial bicarbonate (HCO $\left.{ }_{3}^{-}\right)$, (D) venous $\mathrm{HCO}_{3}^{-}$, (E) venous potassium $\left(\mathrm{K}^{+}\right)$, (F) venous sodium $(\mathrm{Na}+)$. *Significantly different from Pre within the respective condition $(p<0.05)$. \# Significantly different between conditions $(p<$ 0.05).

BFR (Neto et al., 2016), we hypothesized that the arterial and venous $\mathrm{p}\left(\mathrm{O}_{2}\right)$ and $\operatorname{ct}\left(\mathrm{O}_{2}\right)$ would be reduced during BFR with concurrently rising $\mathrm{p}\left(\mathrm{CO}_{2}\right)$ in the venous system.

The present findings prove a rising metabolic demand in the venous part of the working extremity during BFR by reduced $\mathrm{v}-\mathrm{p}\left(\mathrm{O}_{2}\right)$ and $\mathrm{v}$-ct $\left(\mathrm{O}_{2}\right)$. Furthermore, the detected right shift of the oxygen binding curve, shown by the reduced $\mathrm{v}$ p50, is likely induced by a local metabolic acidosis, since we observed a rise in v-p $\left(\mathrm{CO}_{2}\right)$ as well. Surprisingly, the oxygen supply in the arterial part of the vascular system was increased during BFR. These results are in contrast with the previous mechanistic approach, where a lower arterial blood flow and 
TABLE 3 | Additional outcomes related to blood gas analysis including oximetry and electrolyte data.

p-values from 2 way ANOVA

\section{Condition}

Pre

Post-Set 1

Post-Set 2 Post-Set 3

Post-Set 45 min Post-Ex.

Time Condition Interaction

\begin{tabular}{|c|c|c|c|c|c|c|c|c|c|c|}
\hline \multicolumn{11}{|c|}{ BLOOD GASES/OXIMETRY } \\
\hline \multirow[t]{2}{*}{$\mathrm{a}-\mathrm{p}\left(\mathrm{O}_{2}\right)[\mathrm{mmHg}]$} & Control & $95 \pm 5$ & $97 \pm 9$ & $102 \pm 10$ & $100 \pm 10$ & $103 \pm 13$ & $102 \pm 9$ & 0.015 & 0.091 & 0.369 \\
\hline & BFR & $97 \pm 8$ & $109 \pm 13$ & $109 \pm 10$ & $106 \pm 8$ & $102 \pm 8$ & $105 \pm 16$ & & & \\
\hline \multirow[t]{2}{*}{$\mathrm{a}-\mathrm{p}\left(\mathrm{CO}_{2}\right)[\mathrm{mmHg}]$} & Control & $38 \pm 3$ & $39 \pm 4$ & $38 \pm 4$ & $38 \pm 3$ & $38 \pm 3$ & $38 \pm 3$ & 0.7912 & 0.017 & 0.785 \\
\hline & BFR & $36 \pm 3$ & $34 \pm 6$ & $33 \pm 4$ & $33 \pm 4$ & $34 \pm 5$ & $33 \pm 9$ & & & \\
\hline \multirow[t]{2}{*}{ a-p50 [mmHg] } & Control & $25.8 \pm 1.1$ & $26.2 \pm 0.9$ & $26.3 \pm 0.9$ & $26.8 \pm 0.3$ & $26.9 \pm 0.5$ & $26.8 \pm 0.6$ & 0.009 & 0.105 & 0.133 \\
\hline & $\mathrm{BFR}$ & $25.7 \pm 0.5$ & $25.6 \pm 2.1$ & $25.6 \pm 1.9$ & $25.7 \pm 1.5$ & $25.6 \pm 0.9$ & $26.7 \pm 1.4$ & & & \\
\hline \multirow[t]{2}{*}{ v-p50 [mmHg] } & Control & $27.1 \pm 1.5$ & $30.2 \pm 3.6$ & $30.3 \pm 2.3$ & $30.7 \pm 2.0$ & $30.2 \pm 2.3$ & $28.4 \pm 1.5$ & $<0.001$ & 0.065 & 0.028 \\
\hline & BFR & $27.3 \pm 1.7$ & $32.3 \pm 2.6$ & $33.0 \pm 2.1$ & $32.6 \pm 1.8$ & $32.2 \pm 2.3$ & $28.3 \pm 2.0$ & & & \\
\hline \multirow[t]{2}{*}{ a.ctHb $\left[\mathrm{g} \cdot \mathrm{dL}^{-1}\right]$} & Control & $16.0 \pm 1.0$ & $16.3 \pm 0.9$ & $16.3 \pm 0.9$ & $16.3 \pm 0.7$ & $16.2 \pm 0.9$ & $16.2 \pm 0.8$ & $<0.001$ & 0.714 & 0.039 \\
\hline & BFR & $15.7 \pm 1.9$ & $16.3 \pm 1.3$ & $16.6 \pm 1.5$ & $16.7 \pm 1.3$ & $16.7 \pm 1.3$ & $16.4 \pm 1.3$ & & & \\
\hline \multirow[t]{2}{*}{ v.ctHb $\left[\mathrm{g} \cdot \mathrm{dL}^{-1}\right]$} & Control & $15.6 \pm 1.3$ & $15.4 \pm 1.9$ & $16.1 \pm 0.8$ & $16.6 \pm 0.7$ & $16.4 \pm 0.7$ & $15.7 \pm 1.1$ & $<0.001$ & 0.045 & 0.239 \\
\hline & BFR & $15.6 \pm 2.2$ & $16.6 \pm 1.5$ & $17.5 \pm 0.6$ & $17.5 \pm 1.1$ & $17.5 \pm 1.4$ & $15.5 \pm 1.8$ & & & \\
\hline \multirow[t]{2}{*}{ a. $\mathrm{FO}_{2} \mathrm{Hb}[\%]$} & Control & $97.2 \pm 0.7$ & $97.2 \pm 0.8$ & $97.6 \pm 0.6$ & $97.4 \pm 0.4$ & $97.5 \pm 0.6$ & $97.6 \pm 0.6$ & 0.096 & 0.174 & 0.113 \\
\hline & BFR & $97.5 \pm 0.6$ & $97.9 \pm 0.9$ & $98 \pm 0.7$ & $97.9 \pm 1.0$ & $97.8 \pm 0.7$ & $97.5 \pm 0.5$ & & & \\
\hline \multirow[t]{2}{*}{ v. $\mathrm{FO}_{2} \mathrm{Hb}[\%]$} & Control & $78.7 \pm 11.2$ & $71.4 \pm 18.6$ & $67.7 \pm 17.6$ & $66.2 \pm 18.9$ & $69.9 \pm 17.9$ & $84.0 \pm 8.2$ & $<0.001$ & 0.033 & 0.002 \\
\hline & BFR & $76.7 \pm 14.4$ & $46.1 \pm 21.5^{\#}$ & $47.6 \pm 18.5$ & $49.2 \pm 19.7$ & $48.4 \pm 22.8^{\#}$ & $82.1 \pm 13.3$ & & & \\
\hline \multicolumn{11}{|l|}{ ELECTROLYTES } \\
\hline \multirow[t]{2}{*}{$\mathrm{a}\left[\mathrm{K}^{+}\right]\left[\mathrm{mmol} \cdot \mathrm{L}^{-1}\right]$} & Control & $4.0 \pm 0.3$ & $4.4 \pm 0.2$ & $4.3 \pm 0.3$ & $4.4 \pm 0.2$ & $4.3 \pm 0.4$ & $4.0 \pm 0.3$ & $<0.001$ & 0.478 & 0.210 \\
\hline & BFR & $3.8 \pm 0.4$ & $4.3 \pm 0.3$ & $4.4 \pm 0.3$ & $4.3 \pm 0.3$ & $4.3 \pm 0.4$ & $3.8 \pm 0.2$ & & & \\
\hline \multirow[t]{2}{*}{$\mathrm{a}\left[\mathrm{Na}^{+}\right]\left[\mathrm{mmol} \cdot \mathrm{L}^{-1}\right]$} & Control & $139.4 \pm 1.8$ & $139.7 \pm 1.9$ & $140.0 \pm 2.5$ & $139.3 \pm 1.8$ & $138.8 \pm 2.2$ & $137.7 \pm 1.8$ & $<0.001$ & 0.532 & 0.205 \\
\hline & BFR & $139.1 \pm 2.1$ & $138.8 \pm 2.0$ & $138.8 \pm 1.6$ & $138.7 \pm 1.7$ & $138.7 \pm 1.9$ & $138.0 \pm 0.8$ & & & \\
\hline \multirow[t]{2}{*}{$\mathrm{a}\left[\mathrm{Ca}^{2+}\right]\left[\mathrm{mmol} \cdot \mathrm{L}^{-1}\right]$} & Control & $1.21 \pm 0.03$ & $1.22 \pm 0.05$ & $1.22 \pm 0.05$ & $1.23 \pm 0.04$ & $1.22 \pm 0.04$ & $1.21 \pm 0.04$ & 0.217 & 0.334 & 0.194 \\
\hline & BFR & $1.19 \pm 0.05$ & $1.21 \pm 0.05$ & $1.20 \pm 0.04$ & $1.21 \pm 0.04$ & $1.21 \pm 0.04$ & $1.20 \pm 0.04$ & & & \\
\hline \multirow[t]{2}{*}{$\mathrm{v}\left[\mathrm{Ca}^{2+}\right]\left[\mathrm{mmol} \cdot \mathrm{L}^{-1}\right]$} & Control & $1.18 \pm 0.10$ & $1.21 \pm 0.14$ & $1.24 \pm 0.07$ & $1.26 \pm 0.05$ & $1.24 \pm 0.06$ & $1.19 \pm 0.08$ & $<0.001$ & 0.052 & 0.862 \\
\hline & BFR & $1.18 \pm 0.11$ & $1.30 \pm 0.11$ & $1.33 \pm 0.06$ & $1.29 \pm 0.09$ & $1.30 \pm 0.07$ & $1.20 \pm 0.05$ & & & \\
\hline \multirow[t]{2}{*}{$\mathrm{a}\left[\mathrm{Cl}^{-}\right]\left[\mathrm{mmol} \cdot \mathrm{L}^{-1}\right]$} & Control & $107.8 \pm 2.8$ & $108.7 \pm 1.9$ & $109.0 \pm 1.8$ & $109.2 \pm 2.3$ & $109.0 \pm 2.1$ & $108.8 \pm 2.2$ & 0.023 & 0.622 & 0.235 \\
\hline & BFR & $108.3 \pm 2.0$ & $108.0 \pm 2.2$ & $109.1 \pm 2.0$ & $109.4 \pm 1.8$ & $110.7 \pm 5.2$ & $109.9 \pm 4.0$ & & & \\
\hline \multirow[t]{2}{*}{$\mathrm{v}\left[\mathrm{Cl}^{-}\right]\left[\mathrm{mmol} \cdot \mathrm{L}^{-1}\right]$} & Control & $109.2 \pm 4.6$ & $110.2 \pm 5.3$ & $109.1 \pm 2.6$ & $107.8 \pm 2.2$ & $108.9 \pm 2.5$ & $110.1 \pm 6.1$ & 0.314 & 0.547 & 0.383 \\
\hline & BFR & $110.7 \pm 5.2$ & $108.9 \pm 3.9$ & $107.7 \pm 2.3$ & $108.3 \pm 2.5$ & $107.3 \pm 2.2$ & $109.0 \pm 2.6$ & & & \\
\hline
\end{tabular}

\#Significantly different between conditions ( $p<0.05)$.

subsequent insufficient supply of the muscle tissue during BFR was assumed to increase metabolic stress (Downs et al., 2014).

Interestingly, similar changes in BGA can be found in retinal branch vein occlusions, where a mechanical blockage of the venous return caused reduced v-p $\left(\mathrm{O}_{2}\right)$ but simultaneously elevated levels in the arterial branch (Yang et al., 2017). Concerning the origin of this finding, authors discussed that although oxygen is continuously supplied by the arterial system, it may not reach the undersupplied areas due to the blood stasis (Lin et al., 2016). Since the present findings support this idea indirectly through the observed rise in $\mathrm{ctHb}$ during BFR, this purely mechanistical approach does not consider potential exercise-induced changes in membrane permeability or oxygen binding capacity. Consequently, this explanation is probably only a partial answer to this unexpected result and should be investigated in future studies.

\section{Electrolytes}

Based on the demonstrated changes in blood gases we assumed that BFR is a more metabolically demanding training regime with greater impact on metabolism and electrolytes. Although the systemic a- $\left[\mathrm{La}^{-}\right]$showed no differences between $\mathrm{CON}$ and $\mathrm{BFR}, \mathrm{v}-\left[\mathrm{La}^{-}\right]$were higher during $\mathrm{BFR}$ which is in line with previous reports (Poton and Polito, 2016). In combination with the described changes in oxygen content and v-p $\left(\mathrm{CO}_{2}\right)$, the increased $\mathrm{La}^{-}$formation supports the theory that the incoming oxygen does not reach the capillary bed of the working tissue despite increased availability in the arterial system.

In addition to the acid-base balance, BFR-training shows pronounced effects on the electrolyte balance. In line with previous reports (Lindinger, 1995), a periodic shift from increased $\left[\mathrm{K}^{+}\right]$during exercise toward a rapid decrease to baseline levels after cessation was evident in both conditions. While increases in $\mathrm{v}-\left[\mathrm{K}^{+}\right]$during normal training are 
continuously provided to systemic circulation, hyperkalemic states were usually only achievable for a short time due to the necessary high-intensities (Vøllestad et al., 1994). Although arterial levels were not more elevated by BFR, $\mathrm{v}-\left[\mathrm{K}^{+}\right]$were higher after the first set of exercise in comparison to CON, which is rapidly washed out into the circulation when the cuff is opened.

In addition to the occlusion-related concentration of electrolytes, the altered acid-base balance with increased $\left[\mathrm{La}^{-}\right]$and hydrogen ions $\left(\left[\mathrm{H}^{+}\right]\right)$in BFR is responsible for the accumulation of $\mathrm{K}^{+}$during exercise as well. Rising $\left[\mathrm{H}^{+}\right]$cause an inhibition of $\mathrm{K}^{+}$-reuptake and simultaneously displace $\mathrm{K}^{+}$ from binding to cellular proteins (Aronson and Giebisch, 2011). While these results are associated with the faster onset of fatigue during BFR (Allen et al., 2008), this disturbed $\mathrm{K}^{+}$-handling is of considerable relevance for the clinical application of the training technique.

Previous studies reported a reduction in muscle $\mathrm{Na}^{+}-\mathrm{K}^{+}$ATPase density in atrophy-affected skeletal muscles in the elderly (Ford et al., 1993), in degenerative joint diseases (Perry et al., 2013), after immobilization (Jebens et al., 1995) or after surgical interventions (Perry et al., 2015). Since these findings indicate a reduced capacity for $\mathrm{K}^{+}$-reuptake (Sejersted and Sjøgaard, 2000), all these conditions could facilitate the onset of hyperkalemic periods $(>5.2 \mathrm{mmol} / \mathrm{L})$ if BFR-training is applied. Indeed, if large muscle groups are involved, BFR-induced enhancement of muscle fiber recruitment (Yasuda et al., 2014) cause a linear rise in $\mathrm{K}^{+}$-release (Medbø and Sejersted, 1990), which may exceed the reuptake capacity of the affected skeletal muscle tissue (Shushakov et al., 2007). Accordingly, particularly during the first sessions with BFR, post-exercise cuff release is able to cause a temporary rise in systemic $\left[\mathrm{K}^{+}\right]$, which could increase the risk of arrhythmias in patients with compromised cardiovascular health (Paterson, 1996; Gupta et al., 2008).

Taken together, our findings illustrate the acute physiological response of a first time BFR-training, which are significantly reduced after repetitive application of BFR. In this context, Christiansen et al. (2019) found a greater improvement in endurance performance after a 6-week interval training with $\mathrm{BFR}$, which was accompanied by a reduced net $\mathrm{K}^{+}$-release from thigh muscles. Since such a physiological adaptation was also associated with a reduced $\mathrm{La}^{-}$-release (Christiansen et al., 2020), the importance of the acid-base balance for the homeostasis of $\left[\mathrm{K}^{+}\right]$becomes evident.

\section{CLINICAL CONSIDERATIONS}

BFR-training provides a new possibility for physically compromised patients to develop or regain muscle strength, mass and prevent atrophy. However, as BFR is associated with higher SBP and PVP, training in patients with vascular disorders might not be appropriate, i.e., hypertension, heart failure or venous insufficiency. The sympathetic overactivity known

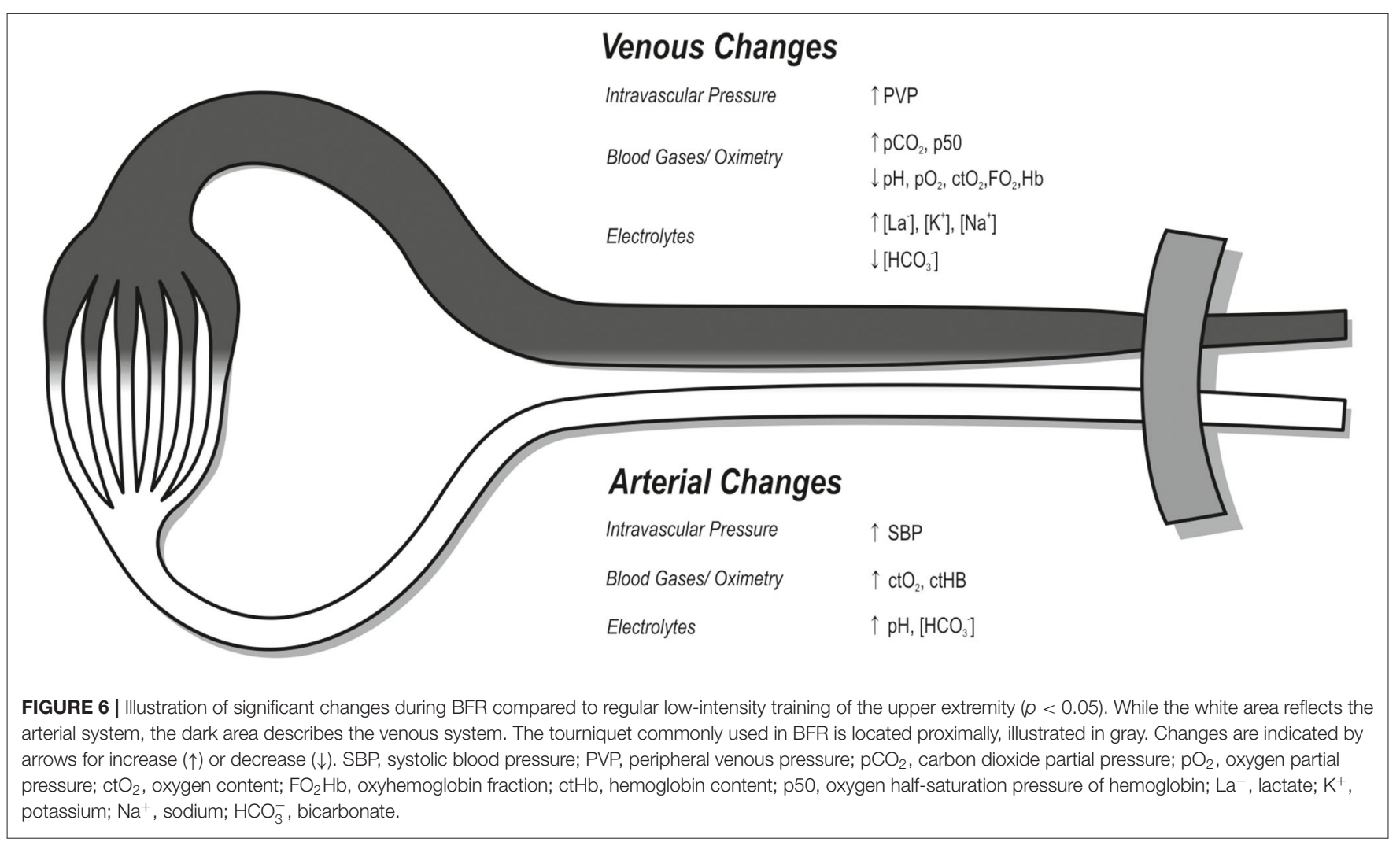


to be present in these disorders could blunt the metaboreflexmediated responses required to deal with the increased metabolic demand associated with BFR-training (Spranger et al., 2015). Furthermore, the current knowledge of BFR-associated changes in electrolytes and their impact during exercise and recovery is poor. For this purpose, future studies need to investigate the effects of these acute responses in order to support a safe application in the medical field (Figure 6).

\section{LIMITATIONS}

The present study examined the effects of BFR on changes in intravascular pressures, blood gases and electrolytes by using an invasive approach with an arterial and venous catheter system. Although the radial artery originates from the brachial artery which supplies the biceps brachii muscle, its puncture at the wrist and the following analyzation of blood samples do not represent the exact physiological arterial conditions by which the biceps muscle is supplied. Additionally, the rete venosum dorsale manus does not reflect the specific drainage area of the biceps muscles, which should be taking into account when interpreting our findings. However, since the invasive catheter method on the upper limbs is routinely not practicable otherwise, we believe that the present findings can be confidently used to interpret changes within the intravascular system during BFR-training.

Furthermore, the sample characteristics as well as the intensity of the compared exercises limits the generalizability of the study outcome. Since the included subjects were experienced in resistance training, former studies in untrained subjects revealed unexpectedly strong physiological responses, even to regular training intensites (Franz et al., 2018). Therefore, the physiological response to BFR-training in a group of untrained subjects would probably be even more pronounced. Additionally, BFR application caused rapid fatigure in the present study so that not all 75 repetitions could be performed, which was different to CON. To assess the valid differences between CON and BFR, future studies should investigate exercise to volutional failure under both conditions.

Finally, from a practical point of view, it should be highlighted that prior to any application of BFR, i.e., in clinical populations, caution should be taken considering that the application of BFR creates a physiological condition in the body that the patient has never experienced before.

\section{DATA AVAILABILITY STATEMENT}

The original contributions presented in the study are included in the article/Supplementary Materials, further inquiries can be directed to the corresponding author/s.

\section{REFERENCES}

Allen, D. G., Lamb, G. D., and Westerblad, H. (2008). Skeletal muscle fatigue: cellular mechanisms. Physiol. Rev. 88, 287-332. doi: 10.1152/physrev.00015.2007

Arnoldi, C. C. (1965). Venous pressure in the leg of healthy human subjects at rest and during muscular exercise in the nearly erect position. Acta Chir. Scand. $130,570-583$.

\section{ETHICS STATEMENT}

This study was reviewed and approved by the Ethics Committee of the University Hospital Duesseldorf, Moorenstrasse 5, DE-40223, Duesseldorf, Germany. The participants provided their written informed consent to participate in this study.

\section{AUTHOR'S NOTE}

The authors affirm that this manuscript is an honest, accurate, and transparent account of the study being reported; that no important aspects of the study have been omitted; and that any discrepancies from the study as planned have been explained.

\section{AUTHOR CONTRIBUTIONS}

AF was responsible for study conception, conduction, evaluation and manuscript preparation. FB collected and interpretated the non-invasive data and was involved in the realization of the study. JR collected and interpretated the invasive data and was involved in the realization of the study. J-FH was responsible for statistical analyzation of the obtained data and writing the manuscript. $\mathrm{CZ}$ and $\mathrm{MB}$ were responsible for the conception and preparation of the study protocol, study execution and writing the manuscript. All authors read and approved the final manuscript.

\section{ACKNOWLEDGMENTS}

The results of the study are presented clearly, honestly, and without fabrication, falsification, or inappropriate data manipulation, and the results of the present study do not constitute endorsement by Frontiers in Physiology. We thank Delfi Medical Inc., (Vancouver, Canada) for providing us a PBFRsystem device for the duration of the study.

\section{SUPPLEMENTARY MATERIAL}

The Supplementary Material for this article can be found online at: https://www.frontiersin.org/articles/10.3389/fphys. 2020.617668/full\#supplementary-material

Supplemental Figure 1 | Blood gas parameters. * Significantly different from Pre within the respective condition $(p<0.05)$. $\mathrm{pO}_{2}$, partial pressure of oxygen; $\mathrm{pCO}_{2}$, partial pressure of carbon dioxide; $p 50$, oxygen half-saturation pressure of hemoglobin; $\mathrm{ctHb}$, hemoglobin content; $\mathrm{FO}_{2} \mathrm{Hb}$, oxyhemoglobin fraction.

Supplemental Figure 2 | Electrolytes. *Significantly different from Pre within the respective condition $(p<0.05)$. \#Significantly different between conditions $(p<$ 0.05). $\mathrm{K}^{+}$, potassium; $\mathrm{Na}^{+}$, sodium; $\mathrm{Ca}^{2+}$, calcium; $\mathrm{Cl}^{-}$, chloride.

Aronson, P. S., and Giebisch, G. (2011). Effects of pH on potassium: new explanations for old observations. J. Am. Soc. Nephrol. 22, 1981-1989. doi: 10.1681/ASN.2011040414

Brandner, C. R., Kidgell, D. J., and Warmington, S. A. (2015). Unilateral bicep curl hemodynamics: low-pressure continuous vs high-pressure intermittent blood flow restriction. Scand. J. Med. Sci. Sports 25, 770-777. doi: 10.1111/sms.12297 Christiansen, D., Eibye, K., Hostrup, M., and Bangsbo, J. (2020). Training with blood flow restriction increases femoral artery diameter and thigh oxygen 
delivery during knee-extensor exercise in recreationally trained men. J. Physiol. (Lond) 598, 2337-2353. doi: 10.1113/JP279554

Christiansen, D., Eibye, K. H., Rasmussen, V., Voldbye, H. M., Thomassen, M., Nyberg, M., et al. (2019). Cycling with blood flow restriction improves performance and muscle $\mathrm{K}+$ regulation and alters the effect of anti-oxidant infusion in humans. J. Physiol. (Lond) 597, 2421-2444. doi: 10.1113/JP277657

Conceição, M. S., and Ugrinowitsch, C. (2019). Exercise with blood flow restriction: an effective alternative for the non-pharmaceutical treatment for muscle wasting. J. Cachexia Sarcopenia Muscle 10, 257-262. doi: $10.1002 /$ jcsm. 12397

Cristina-Oliveira, M., Meireles, K., Spranger, M. D., O'Leary, D. S., Roschel, H., and Peçanha, T. (2020). Clinical safety of blood flow-restricted training? A comprehensive review of altered muscle metaboreflex in cardiovascular disease during ischemic exercise. Am. J. Physiol. Heart Circ. Physiol. 318, H90-H109. doi: 10.1152/ajpheart.00468.2019

Downs, M. E., Hackney, K. J., Martin, D., Caine, T. L., Cunningham, D., O'Connor, D. P., et al. (2014). Acute vascular and cardiovascular responses to blood flow-restricted exercise. Med. Sci. Sports Exerc. 46, 1489-1497. doi: 10.1249/MSS.0000000000000253

Ford, G. A., Blaschke, T. F., Wiswell, R., and Hoffman, B. B. (1993). Effect of aging on changes in plasma potassium during exercise. J. Gerontol. 48, M140-M145. doi: 10.1093/geronj/48.4.M140

Franz, A., Behringer, M., Harmsen, J.-F., Mayer, C., Krauspe, R., Zilkens, C., et al. (2018). Ischemic preconditioning blunts muscle damage responses induced by eccentric exercise. Med. Sci. Sports Exerc. 50, 109-115. doi: 10.1249/MSS.0000000000001406

Freitas, E. D. S., Poole, C., Miller, R. M., Heishman, A. D., Kaur, J., Bemben, D. A., et al. (2017). Time course change in muscle swelling: high-intensity vs. blood flow restriction exercise. Int. J. Sports Med. 38, 1009-1016. doi: 10.1055/s-0043-118342

Gupta, K., Aggarwal, N., Rao, M., Verma, U. C., and Anand, R. (2008). Re-emphasizing the importance of tourniquet time: severe myocardial depression following tourniquet deflation. Acta Anaesthesiol. Scand. 52:873. doi: 10.1111/j.1399-6576.2008.01663.x

Hughes, L., Paton, B., Rosenblatt, B., Gissane, C., and Patterson, S. D. (2017). Blood flow restriction training in clinical musculoskeletal rehabilitation: a systematic review and meta-analysis. Br. J. Sports Med. 51, 1003-1011. doi: 10.1136/bjsports-2016-097071

Hughes, L., Rosenblatt, B., Haddad, F., Gissane, C., McCarthy, D., Clarke, T., et al. (2019). Comparing the effectiveness of blood flow restriction and traditional heavy load resistance training in the post-surgery rehabilitation of anterior cruciate ligament reconstruction patients: a UK National Health Service Randomised Controlled Trial. Sports Med. 49, 1787-1805. doi: 10.1007/s40279-019-01137-2

Hyldahl, R. D., Chen, T. C., and Nosaka, K. (2017). Mechanisms and mediators of the skeletal muscle repeated bout effect. Exerc. Sport Sci. Rev. 45, 24-33. doi: 10.1249/JES.0000000000000095

Jebens, E., Steen, H., Fjeld, T. O., Bye, E., and Sejersted, O. M. (1995). Changes in $\mathrm{Na}+, \mathrm{K}(+)$-adenosinetriphosphatase, citrate synthase and $\mathrm{K}+$ in sheep skeletal muscle during immobilization and remobilization. Eur. J. Appl. Physiol. Occup. Physiol. 71, 386-395. doi: 10.1007/BF00635871

Jessee, M. B., Dankel, S. J., Buckner, S. L., Mouser, J. G., Mattocks, K. T., and Loenneke, J. P. (2017). The cardiovascular and perceptual response to very low load blood flow restricted exercise. Int. J. Sports Med. 38, 597-603. doi: 10.1055/s-0043-109555

Kilgas, M. A., McDaniel, J., Stavres, J., Pollock, B. S., Singer, T. J., and Elmer, S. J. (2019). Limb blood flow and tissue perfusion during exercise with blood flow restriction. Eur. J. Appl. Physiol. 119, 377-387. doi: 10.1007/s00421-0184029-2

Lin, L.-L., Dong, Y.-M., Zong, Y., Zheng, Q.-S., Fu, Y., Yuan, Y.-G., et al. (2016). Study of retinal vessel oxygen saturation in ischemic and nonischemic branch retinal vein occlusion. Int. J. Ophthalmol. 9, 99-107. doi: 10.18240/ijo.2016.01.17

Lindinger, M. I. (1995). Potassium regulation during exercise and recovery in humans: implications for skeletal and cardiac muscle. J. Mol. Cell. Cardiol. 27, 1011-1022. doi: 10.1016/0022-2828(95)90070-5

Loenneke, J. P., Fahs, C. A., Rossow, L. M., Abe, T., and Bemben, M. G. (2012). The anabolic benefits of venous blood flow restriction training may be induced by muscle cell swelling. Med. Hypotheses 78, 151-154. doi: 10.1016/j.mehy.2011.10.014

Lu, Y., Patel, B. H., Kym, C., Nwachukwu, B. U., Beletksy, A., Forsythe, B., et al. (2020). Perioperative blood flow restriction rehabilitation in patients undergoing ACL reconstruction: a systematic review. Orthopaedic J. Sports Med. 8:2325967120906822. doi: 10.1177/2325967120906822

Medbø, J. I., and Sejersted, O. M. (1990). Plasma potassium changes with high intensity exercise. J. Physiol. (Lond) 421, 105-122. doi: 10.1113/jphysiol.1990.sp017935

Minniti, M. C., Statkevich, A. P., Kelly, R. L., Rigsby, V. P., Exline, M. M., Rhon, D. I., et al. (2020). The safety of blood flow restriction training as a therapeutic intervention for patients with musculoskeletal disorders: a systematic review. Am. J. Sports Med. 48, 1773-1785. doi: 10.1177/03635465198 82652

Neto, G. R., Sousa, M. S. C., Costa e Silva, G. V., Gil, A. L. S., Salles, B. F., and Novaes, J. S. (2016). Acute resistance exercise with blood flow restriction effects on heart rate, double product, oxygen saturation and perceived exertion. Clin. Physiol. Funct. Imaging 36, 53-59. doi: 10.1111/cp f.12193

Paterson, D. J. (1996). Antiarrhythmic mechanisms during exercise. J. Appl. Physiol. 80, 1853-1862. doi: 10.1152/jappl.1996.80.6.1853

Patterson, S. D., Hughes, L., Warmington, S., Burr, J., Scott, B. R., Owens, J., et al. (2019). Blood flow restriction exercise: considerations of methodology, application, and safety. Front. Physiol. 10:533. doi: 10.3389/fphys.201 9.01332

Perry, B. D., Levinger, P., Morris, H. G., Petersen, A. C., Garnham, A. P., Levinger, I., et al. (2015). The effects of knee injury on skeletal muscle function, $\mathrm{Na}+, \mathrm{K}+-$ ATPase content, and isoform abundance. Physiol. Reports 3:e12294. doi: 10.14814 phy2.12294

Perry, B. D., Levinger, P., Serpiello, F. R., Caldow, M. K., Cameron-Smith, D., Bartlett, J. R., et al. (2013). The effects of osteoarthritis and age on skeletal muscle strength, $\mathrm{Na}+\mathrm{K}+$-ATPase content, gene and isoform expression. J. Appl. Physiol. 115, 1443-1449. doi: 10.1152/japplphysiol.0078 9.2013

Poton, R., and Polito, M. D. (2015). Hemodynamic responses during lower-limb resistance exercise with blood flow restriction in healthy subjects. J. Sports Med. Phys. Fitness 55, 1571-1577.

Poton, R., and Polito, M. D. (2016). Hemodynamic response to resistance exercise with and without blood flow restriction in healthy subjects. Clin. Physiol. Funct. Imaging 36, 231-236. doi: 10.1111/cpf.12218

Sarin, S., Scurr, J. H., and Smith, P. D. (1992). Medial calf perforators in venous disease: the significance of outward flow. J. Vasc. Surg. 16, 40-46. doi: 10.1016/0741-5214(92)90415-5

Sato, Y., Yoshitomi, A., and Abe, T. (2005). Acute growth hormone response to low-intensity KAATSU resistance exercise: comparison between arm and leg. Int. J. KAATSU Ttaining Res. 1, 45-50. doi: 10.3806/ijktr.1.45

Scott, B. R., Peiffer, J. J., Thomas, H. J., Marston, K. J., and Hill, K. D. (2018). Hemodynamic responses to low-load blood flow restriction and unrestricted high-load resistance exercise in older women. Front. Physiol 9:1324. doi: 10.3389/fphys.2018.01324

Sejersted, O. M., and Sjøgaard, G. (2000). Dynamics and consequences of potassium shifts in skeletal muscle and heart during exercise. Physiol. Rev. 80, 1411-1481. doi: 10.1152/physrev.2000.80.4.1411

Shushakov, V., Stubbe, C., Peuckert, A., Endeward, V., and Maassen, N. (2007). The relationships between plasma potassium, muscle excitability and fatigue during voluntary exercise in humans. Exp. Physiol. 92, 705-715. doi: 10.1113/expphysiol.2006.036384

Spranger, M. D., Krishnan, A. C., Levy, P. D., O'Leary, D. S., and Smith, S. A. (2015). Blood flow restriction training and the exercise pressor reflex: a call for concern. Am. J. Physiol. Heart Circ. Physiol. 309, H1440-H1452. doi: 10.1152/ajpheart.00208.2015

Tansey, E. A., Montgomery, L. E. A., Quinn, J. G., Roe, S. M., and Johnson, C. D. (2019). Understanding basic vein physiology and venous blood pressure through simple physical assessments. Adv. Physiol. Educ. 43, 423-429. doi: 10.1152/advan.00182.2018

Vøllestad, N. K., Hallén, J., and Sejersted, O. M. (1994). Effect of exercise intensity on potassium balance in muscle and blood of man. J. Physiol. (Lond) 475, 359-368. doi: 10.1113/jphysiol.1994.sp020077 
Wan, H.-Y., Weavil, J. C., Thurston, T. S., Georgescu, V. P., Hureau, T. J., Bledsoe, A. D., et al. (2020). The exercise pressor reflex and chemoreflex interaction: cardiovascular implications for the exercising human. J. Physiol. (Lond) 598, 2311-2321. doi: 10.1113/JP279456

Wernbom, M., Paulsen, G., Nilsen, T. S., Hisdal, J., and Raastad, T. (2012). Contractile function and sarcolemmal permeability after acute low-load resistance exercise with blood flow restriction. Eur. J. Appl. Physiol. 112, 2051-2063. doi: 10.1007/s00421-011-2172-0

Yang, J.-Y., You, B., Wang, Q., Chan, S. Y., Jonas, J. B., and Wei, W.-B. (2017). Retinal vessel oxygen saturation in healthy subjects and early branch retinal vein occlusion. Int. J. Ophthalmol. 10, 267-270. doi: 10.18240/ijo.2017.02.14

Yasuda, T., Fukumura, K., Fukuda, T., Iida, H., Imuta, H., Sato, Y., et al. (2014). Effects of low-intensity, elastic band resistance exercise combined with blood flow restriction on muscle activation. Scand. J. Med. Sci. Sports 24, 55-61. doi: 10.1111/j.1600-0838.2012.01489.x
Zavorsky, G. S., Lands, L. C., Schneider, W., and Carli, F. (2005). Comparison of fingertip to arterial blood samples at rest and during exercise. Clin. J. Sport Med. 15, 263-270. doi: 10.1097/01.jsm.0000171287.99174.b7

Conflict of Interest: The authors declare that the research was conducted in the absence of any commercial or financial relationships that could be construed as a potential conflict of interest.

Copyright $\odot 2020$ Franz, Berndt, Raabe, Harmsen, Zilkens and Behringer. This is an open-access article distributed under the terms of the Creative Commons Attribution License (CC BY). The use, distribution or reproduction in other forums is permitted, provided the original author(s) and the copyright owner(s) are credited and that the original publication in this journal is cited, in accordance with accepted academic practice. No use, distribution or reproduction is permitted which does not comply with these terms. 